\title{
Infantile haemangioma: 5-year experience at the vascular anomaly clinic
}

\author{
Amr Abdelhamid AbouZeid ${ }^{*}$ (D), Iman A. Ragab², Shaimaa Abdelsattar Mohammad ${ }^{3}$, Wael Ahmed Ghanem', \\ Haytham Mohamed Nasser $^{4}$ and Osama El-Naggar ${ }^{1}$
}

\begin{abstract}
Background: Infantile haemangiomas $(I H)$ represent a common benign vascular tumour affecting the paediatric population. Infantile haemangiomas are characterised by a natural history differentiating it from other vascular anomalies. After a transient proliferative phase in early infancy, the tumour passes through a plateau phase before going into spontaneous involution. In this report, we tried to share our experience over the last 5 years in managing cases presenting with $\mathrm{IH}$ at a specialised vascular anomaly clinic.

Main body of abstract: This report included cases of $\mathrm{IH}$ who were attending the vascular anomaly clinic during the period 2015 through 2019. Data of all patients attending the clinic were retrospectively examined. Files of 103 cases with $\mathrm{IH}$ were available for review. The diagnosis of $\mathrm{IH}$ was usually straight forward owing to the typical history and characteristic findings at clinical examination. A significant female predominance was noticed. Generally, $I H$ were more common in the head and neck region (70\%). Active intervention was necessary in specific situations (eye occlusion, airway involvement, large lesions with skin ulcerations). Whenever intervention proved to be necessary, propranolol was chosen as the first line of treatment with a favourable response detected in about $90 \%$ of cases. Surgery was still a valid option (6\%) for lesions amenable to resection; however, we must put in consideration that most lesions will spontaneously regress.

Conclusion: Infantile haemangiomas are common benign vascular tumours of infancy with relatively few complications. Cosmesis is a major concern especially for lesions affecting the face. Propranolol can induce tumour regression in most cases, and generally, a favourable outcome can be anticipated.
\end{abstract}

Keywords: Haemangioma, Multidisciplinary team, Vascular anomalies, Propranolol, Magnetic resonance imaging

\section{Background}

Infantile haemangiomas $(\mathrm{IH})$ constitute the majority of vascular tumours [1], besides being the most common soft tissue tumour in children [2]. Infantile haemangiomas $(\mathrm{IH})$ are characterised by significant heterogeneity with variable presentations affecting different parts of the body [2,3]. A female predilection has been reported [1-3]; also, IH have been shown to be more common with prematurity and among fair-skinned people $[2,3]$.

\footnotetext{
* Correspondence: amrabdelhamid@hotmail.com

'Pediatric Surgery Department, Faculty of Medicine, Ain Shams University, Cairo, Egypt

Full list of author information is available at the end of the article
}

Typically, IH are not present (or very small) at birth; then, the tumour follows a characteristic natural history: rapid proliferative phase (1st year of life), plateau phase, and then goes into spontaneous involution [2].

In 1982, Mulliken and Glowacki proposed their famous classification differentiating between haemangiomas (vascular tumours) and other vascular malformations (hamartomas) [4]. Their classification gained widespread acceptance and succeeded in removing many of the misunderstandings that have accumulated over years from confusing terminology [3]. The classification has been adopted and modified by the International Society for the Study of Vascular Anomalies (ISSVA) in 1996 with further update in 2014 [5]. Another milestone in the

\section{Springer Open}

(c) The Author(s). 2021 Open Access This article is licensed under a Creative Commons Attribution 4.0 International License, which permits use, sharing, adaptation, distribution and reproduction in any medium or format, as long as you give appropriate credit to the original author(s) and the source, provide a link to the Creative Commons licence, and indicate if changes were made. The images or other third party material in this article are included in the article's Creative Commons licence, unless indicated otherwise in a credit line to the material. If material is not included in the article's Creative Commons licence and your intended use is not permitted by statutory regulation or exceeds the permitted use, you will need to obtain permission directly from the copyright holder. To view a copy of this licence, visit http://creativecommons.org/licenses/by/4.0/. 
history of vascular anomalies was the introduction of propranolol to induce regression of $\mathrm{IH}$ [6]; several centres reported a high success rate with propranolol in treating $\mathrm{IH}$ with strong level of evidence [2].

In this report, we present our experience over the last 5 years in managing cases of $\mathrm{IH}$ at a multidisciplinary vascular anomaly clinic.

\section{Main text}

This report included cases of $\mathrm{IH}$ who were attending the vascular anomaly clinic during the period 2015 through 2019. Other vascular tumours (congenital haemangioma, haemangioendotheliomas) were excluded for having a different management protocol. Also, cases of hepatic haemangiomas were excluded to be discussed in a separate report. Owing to the retrospective nature of the study, an IRB number was not required, and the study was approved through expedited review by the scientific/ethical committee of the Pediatric Surgery department.

\section{Multidisciplinary approach}

The idea of a multidisciplinary vascular anomaly clinic was first introduced at our institution by late professor Alaa Hamza in 2008. Currently, the vascular anomaly clinic is held once every 2 weeks (twice per month). The clinic is regularly attended by paediatric surgeons and paediatricians (haematology/oncology) who manage cases together in an integrated manner (interdisciplinary approach) [7]. Paediatric radiologists review all available imaging studies to be discussed with the clinical team highlighting the differential diagnoses and important anatomical findings. Colleagues from other specialities (interventional radiology, ENT, plastic surgery, neurosurgery, ophthalmology, etc.) are consulted independently in specific situations as required (multidisciplinary approach) [7]. At his first visit to the clinic, each patient receives a follow-up card carrying his diagnosis, while follow-up notes can be added successively with further visits. Data including patients' photographs and investigations are stored in an electronic form on a personal computer. Only regular staff members who are running the vascular anomaly clinic are allowed to access the patients' data with special attention to hide the patients' identity in any presentation or publication. The parents are informed about the importance of saving medical data of their children to be available for future studies and interpretations that will serve to improve medical service supplied for children with similar disease.

Digital archiving of 103 cases with IH was available for review. Most of these were cases that had an indication for active intervention (either medical or surgical treatment). A significant female predominance was noticed (female to male ratio $=3: 1$ ). Infantile haemangiomas presented either as segmental (18\%) or more commonly a localised lesion (82\%) (Fig. 1). Diffuse (segmental) lesions were noticed to affect the head and neck, trunk, or limbs. Four cases presented with multiple cutaneous haemangiomas (more than three); two of them had associated visceral lesions (liver). Generally, IH were more common in the head and neck region (about 70\% in this case series). Table 1 demonstrates the distribution of $\mathrm{IH}$ through different parts of the body among cases included in the study. Skin ulcerations were noticed during the rapid proliferative phase of $\mathrm{IH}$ in certain regions: genitalia, upper limbs, breast, and periauricular (Fig. 2).

\section{Diagnosis}

In most cases, the diagnosis was made on a clinical background (typical history and characteristic appearance; Fig. 1). Investigations (Doppler ultrasound, MRI) were only required for atypical cases, to search for associated anomalies, and before intervention (surgery/injection) if it turned to be necessary [3, 8]. Doppler ultrasound can confirm the presence of 'high' arterial flow differentiating $\mathrm{IH}$ from other low flow vascular anomalies. MRI proved to be superior in demonstrating anatomical details of lesions with deeper extensions (e.g. the parotid gland). Typical MRI findings (Figs. 3 and 4) included a well-defined 'mass lesion' with characteristic 'flow voids' (in T1 and T2WI) that showed avid enhancement after IV contrast injection $[8,9]$.

\section{Medical treatment}

Cases with $\mathrm{IH}$ can be managed expectantly by waiting for spontaneous involution $[1,10]$. This often requires repeated reassurance for the parents as complete regression may be delayed up to the age of 7-9 years [1]. Digital photography of cases successfully managed conservatively can be of great help in reassuring anxious family members (Fig. 5). Active intervention is necessary in specific situations (eye occlusion, Fig. 6; airway involvement; large lesions with skin ulcerations) [1]. IH affecting the face raise major parental concerns urging for early intervention to avoid social stress on the child and his family [2].

Whenever intervention proved to be necessary, propranolol was chosen as the first line of treatment. An oral dose of $2 \mathrm{mg} / \mathrm{kg} /$ day in three divided doses was generally well tolerated (no complications detected in this case series) with a favourable response in about $90 \%$ of cases. The favourable response was in the form of either inducing partial/complete regression (Figs. 2 and 7) or at least interruption of the proliferative phase of the tumour. Before we start oral propranolol treatment, we have to exclude history of congenital heart disease and bronchial asthma. We can start as early as during the neonatal period (usually, IH do not present at birth, but 

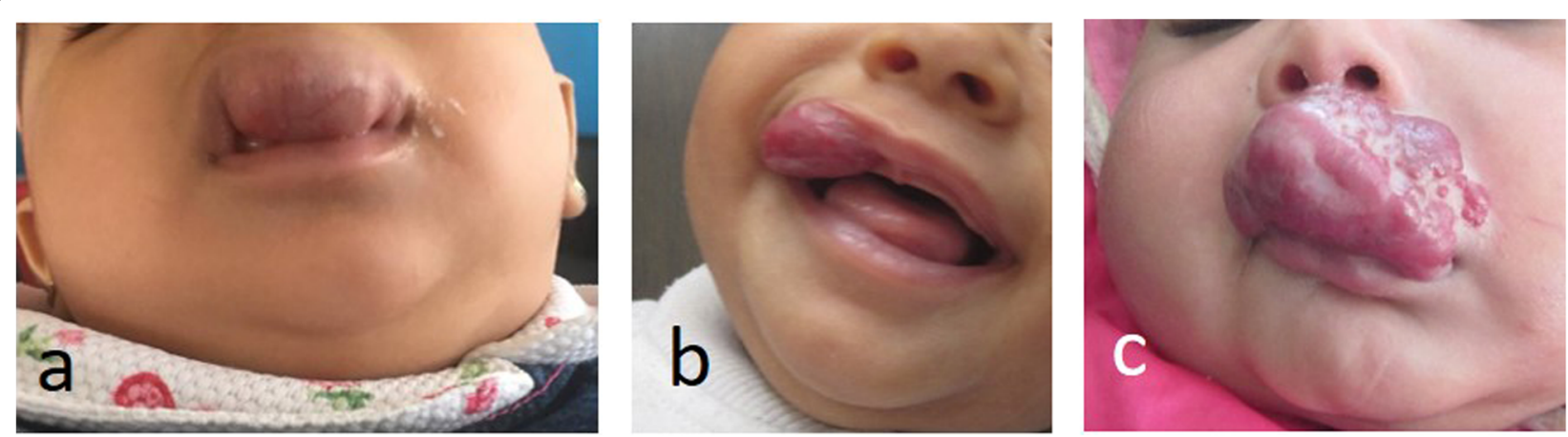

Fig. 1 Infantile haemangioma of the upper lip in three different cases showing the characteristic appearance of red, compressible papules

rather few weeks later). We may start at a lower oral dose $(1 \mathrm{mg} / \mathrm{kg} /$ day $)$ for 2 weeks; then, we shift to $2 \mathrm{mg} /$ $\mathrm{kg} /$ day; in severe cases (airway affection), we may reach $3 \mathrm{mg} / \mathrm{kg} /$ day [1, 2]. Early, when we first started to use propranolol in treatment of $\mathrm{IH}$, we used to hospitalise these cases to monitor for any significant changes in their heart rate; later, we have found that to be unnecessary [11]. Alternatively, small superficial lesions can be managed by topical application of timolol maleate solution/gel [12]. Guided by the clinical response (tumour regression) and tumour site-related complications, oral propranolol may be discontinued after reaching the age of $1-2$ years (usually gradual tapering of dose over $2-3$ months). Very occasionally, a relapse (re-increase in tumour size) after drug discontinuation may be an indication to prolong propranolol treatment for further 6 months.

Although propranolol has greatly replaced corticosteroids in the nonsurgical therapy of $\mathrm{IH}$, systemic corticosteroids (prednisolone $2-5 \mathrm{mg} / \mathrm{kg} /$ day) may still have a role as an adjuvant treatment with propranolol in critical

Table 1 The distribution of infantile haemangioma through different parts of the body among cases included in the study

\begin{tabular}{llll}
\hline Head and neck & \multicolumn{3}{l}{ Other parts of the body } \\
\hline Periorbital & 12 & Limbs & 12 \\
Parotid & 12 & Trunk & 9 \\
Scalp & 9 & Breast & 4 \\
Lip & 8 & Genitalia & 4 \\
Cheek & 6 & Sacrum & 1 \\
Nose & 5 & & \\
Forehead & 4 & & \\
Periauricular & 3 & & \\
Submandibular & 2 & & 30 \\
Temporal & 1 & & \\
Other & 11 & & Total \\
Total & 73 & & \\
\hline
\end{tabular}

situations (airway involvement) [11, 13]. In this series, we had two cases of $\mathrm{IH}$ affecting the airway presenting with the characteristic segmental cutaneous lesions in the face 'beard distribution' [13]. The first showed good response to propranolol, while the second case presented at the age of 3 months with severe stridor that required tracheostomy before being referred to our clinic. The latter received a combination of oral propranolol and prednisolone to control breathing difficulties. After some time, corticosteroids were discontinued because of systemic side effects and were replaced by the newly introduced drug 'sirolimus' [14]. The patient is now stable (2 years old) with shrinkage of subglottic lesions and has been referred to an ENT facility to arrange for weaning her from the tracheostomy tube.

Intralesional steroid injection (triamicinolone $2 \mathrm{mg} /$ $\mathrm{kg}$ ) can be used to accelerate tumour regression in small, localised lesions [1, 2] with less predictable outcomes (50\% response). This is usually applied only once or twice to avoid possible complications of repeated subcutaneous injections (skin atrophy/ depigmentation).

\section{Surgical treatment}

Surgery is still a valid option for lesions amenable to resection [1, 2]; however, we must put in consideration that most lesions will spontaneously regress. Surgery was considered a last resort for $\mathrm{IH}$ in this case series where only six cases (6\%) underwent surgical excision. Two of these cases (one in the parotid and the other in the scalp) failed to show any signs of regression with time or with medical treatment (propranolol + several trials of local injection steroids/bleomycin) (Figs. 3 and 8). In a third case, the lesion was located at the nasal tip. Although the lesion showed partial response to medical treatment, yet it was still causing a significant cosmetic problem for the child and her family. The indication for surgery in the other three cases was mainly guided by parents' preference, when the lesion was excised through 

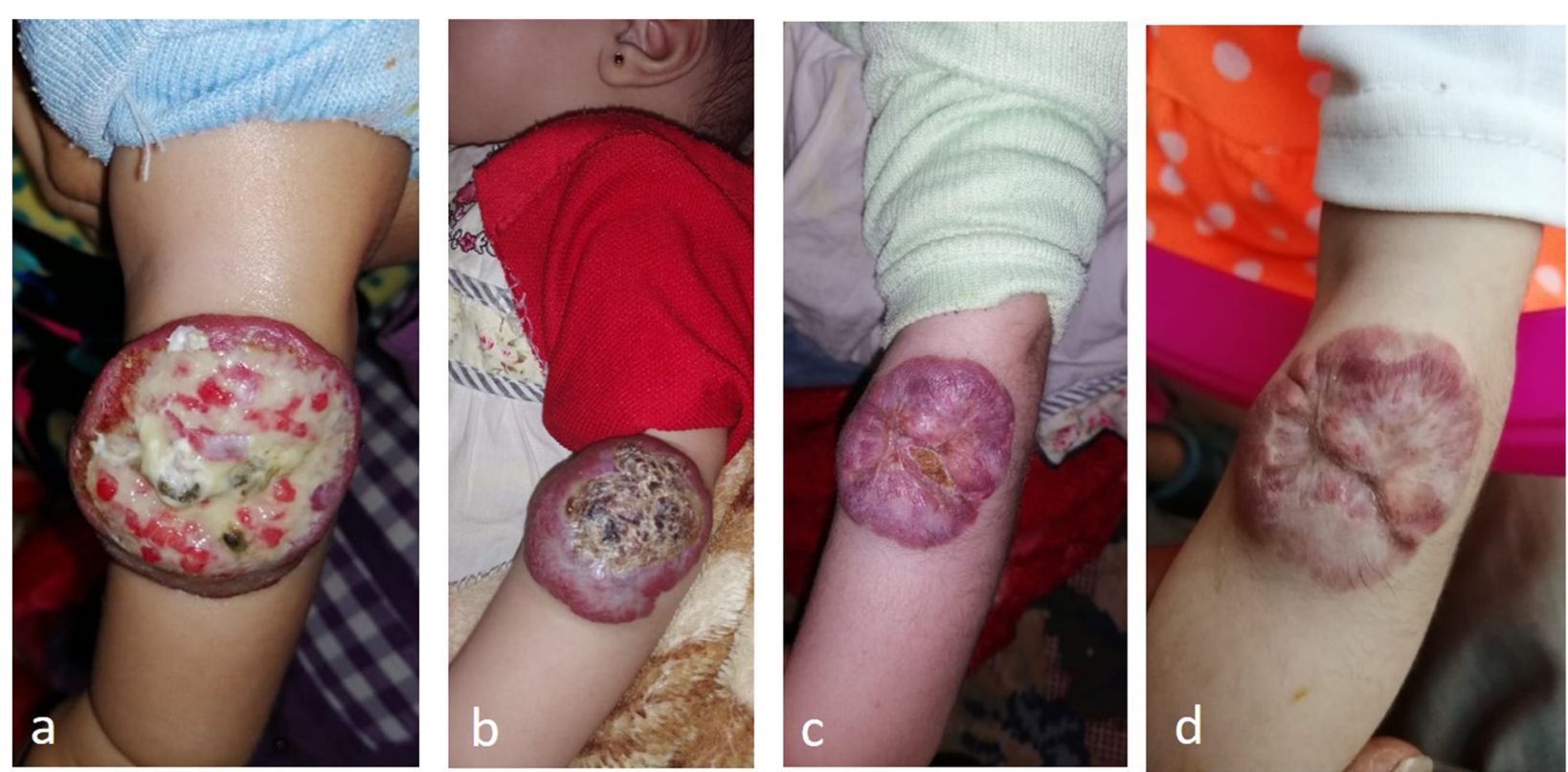

Fig. 2 Infantile haemangioma of the upper limb in the same patient at different stages. a The lesion at the age of 3 months showing marked overlying skin ulcerations during rapid proliferative phase. b, c Progress showing gradual healing by daily dressing and oral propranolol therapy. d Regression of the haemangioma at the age of 18 months
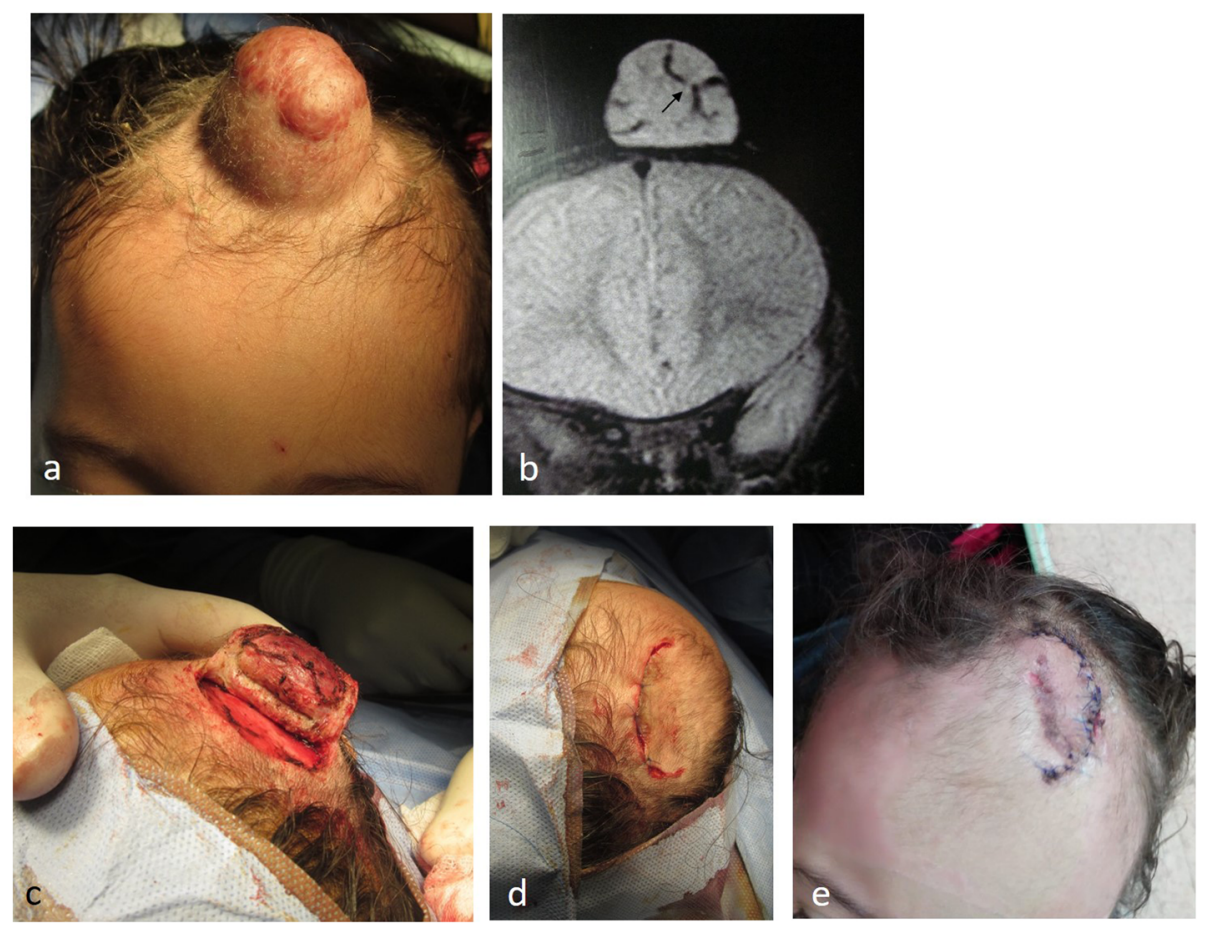

Fig. 3 a Infantile haemangioma of the scalp. b MRI showing typical hyperintense mass lesion with characteristic flow voids (black arrow). c, d, e Failure to respond to medical treatment (oral propranolol, intralesional steroid/bleomycin injection) was an indication for excision at the age of 3 years. Note: the overlying skin was not completely involved giving the chance of sparing a skin flap to be used to cover the skin defect after excision of the mass 


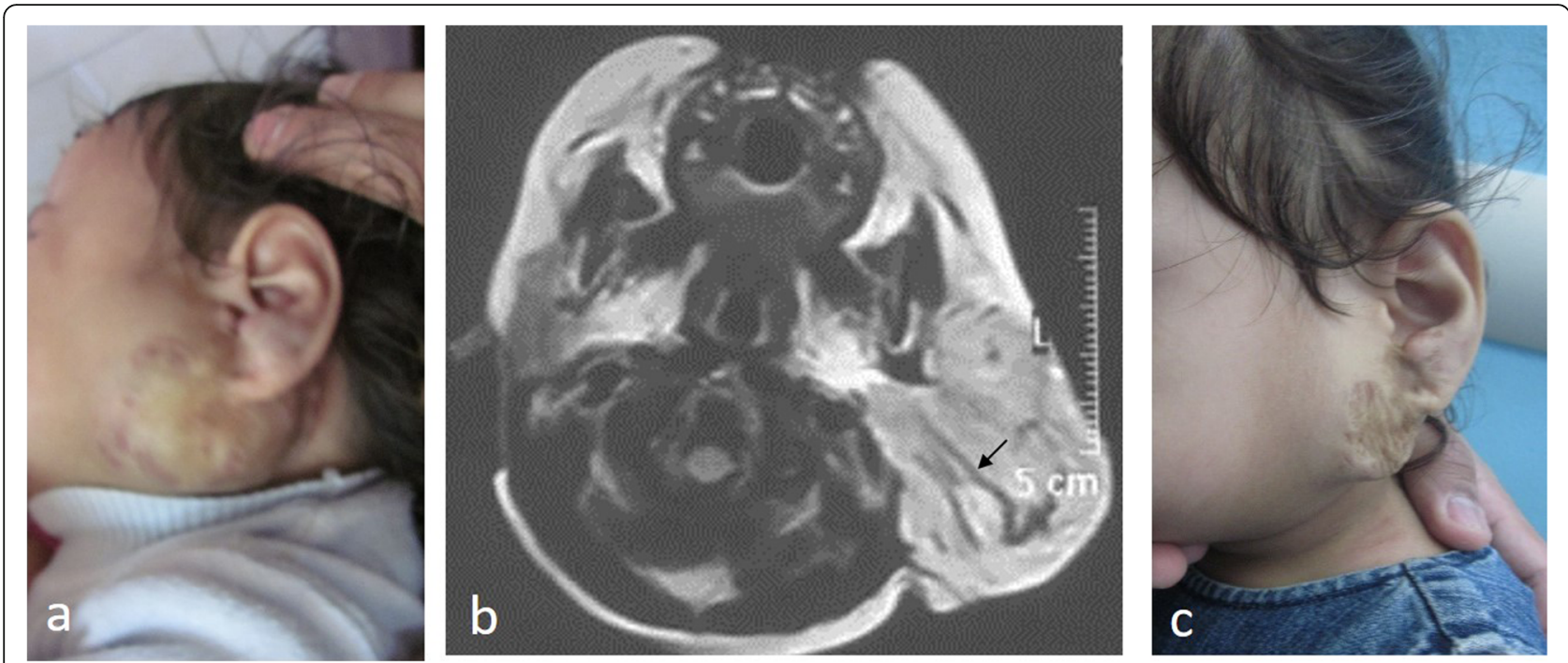

Fig. 4 Infantile haemangioma of the parotid. a The tumour size at presentation (14-month-old girl). b Axial MRI (T2WI) showing typical hyperintense mass lesion with characteristic flow voids (black arrow). c The same patient at 31 months of age showing good response to systemic propranolol and intralesional corticosteroid injection
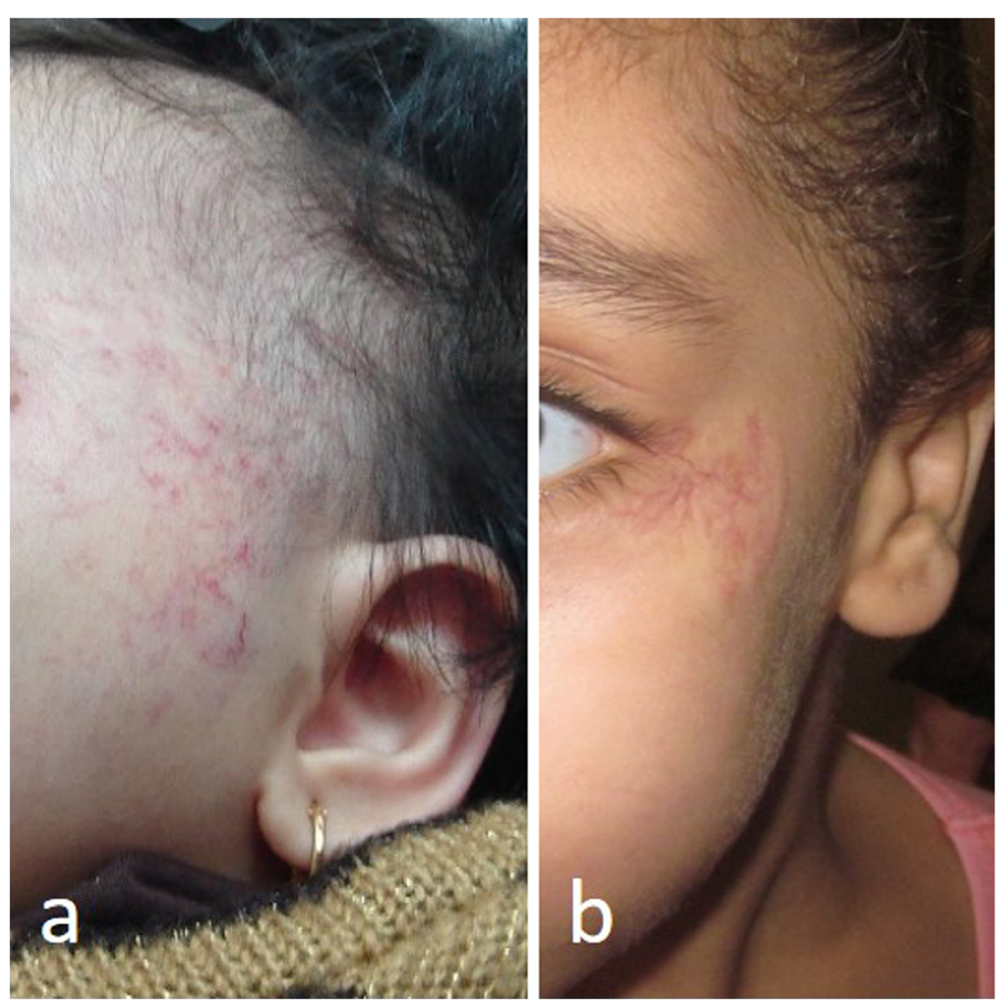

Fig. 5 Infantile haemangioma in the face of two different cases after stoppage of medical treatment and going into involution 

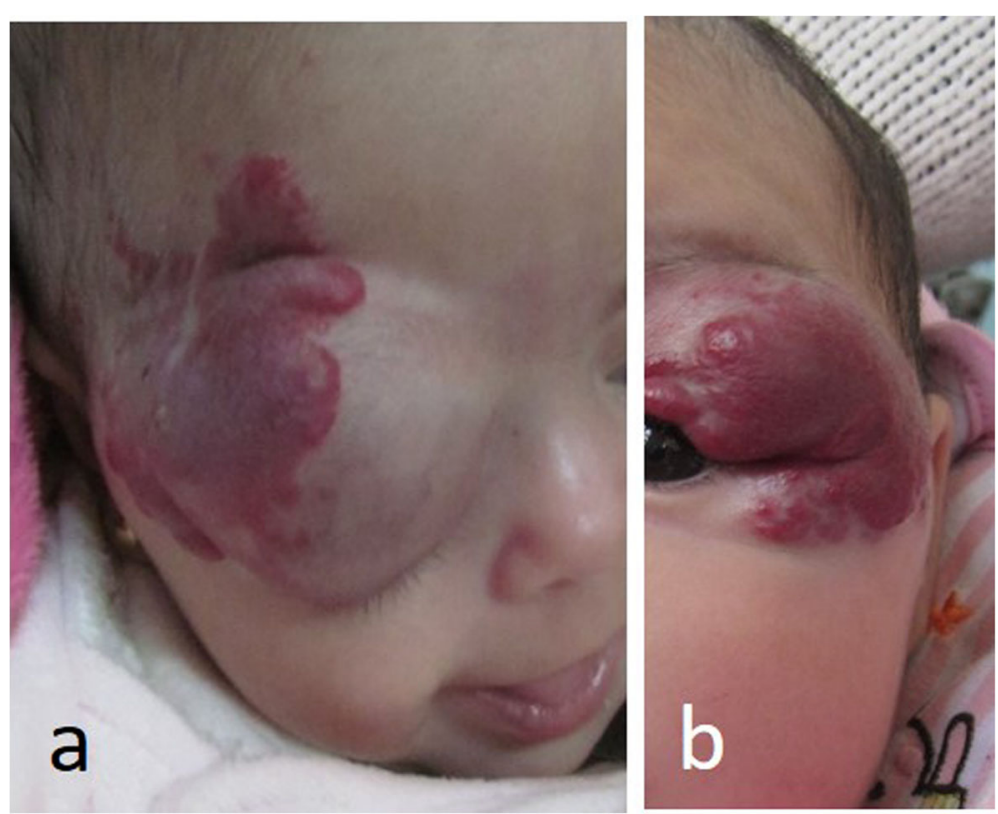

Fig. 6 Periorbital infantile haemangioma in two different cases $(\mathbf{a}, \mathbf{b})$. The visual field of the affected side is greatly compromised in (a)

a small hidden scar. Usually, surgery can be considered after the age of 3-4 years.

\section{Neurological associations}

Neurological associations were detected in three cases with $\mathrm{IH}(3 \%)$. The first presented with a midline haemangioma in the back (low lumbar) that was associated with spina bifida occulta and tethered spinal cord (Fig. 9). The patient did not have motor symptoms nor voiding problems. The other two cases had a segmental haemangioma in the face with associated posterior fossa brain anomalies (PHACE syndrome) [2]. These cases were referred to follow-up their associated conditions at the neurology clinic.

\section{Conclusion}

Infantile haemangiomas represent a major sector (about $50 \%$ ) of cases attending the specialised vascular anomaly clinic. We confirm the previously reported female predominance $(3: 1)[2,3]$. About $80 \%$ of cases present with localised lesions with special predilection to affect the head and neck (70\%) [3]. The benign nature of the disease is obvious in most cases, except for overlying skin ulcerations that may accompany the rapid proliferative
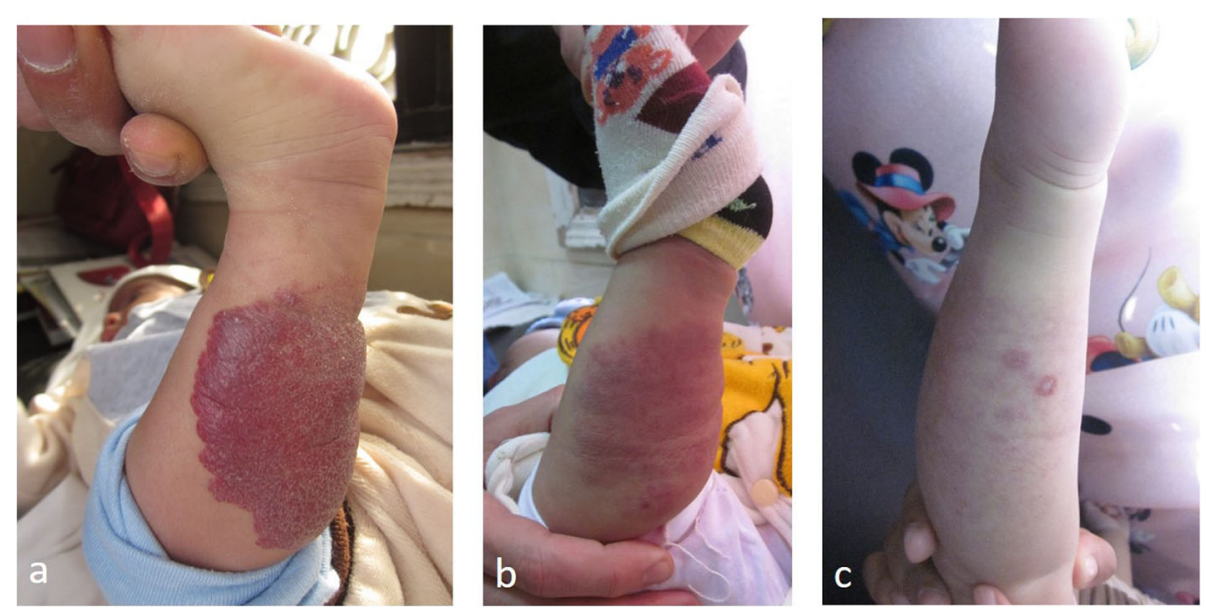

Fig. 7 Infantile haemangioma of the lower limb in the same patient at different stages showing excellent response to propranolol. a The lesion during proliferative phase at the age of 2.5 months. $\mathbf{b}$ The lesion at 7 months. $\mathbf{c}$ Haemangioma regression at the age of 12 months 

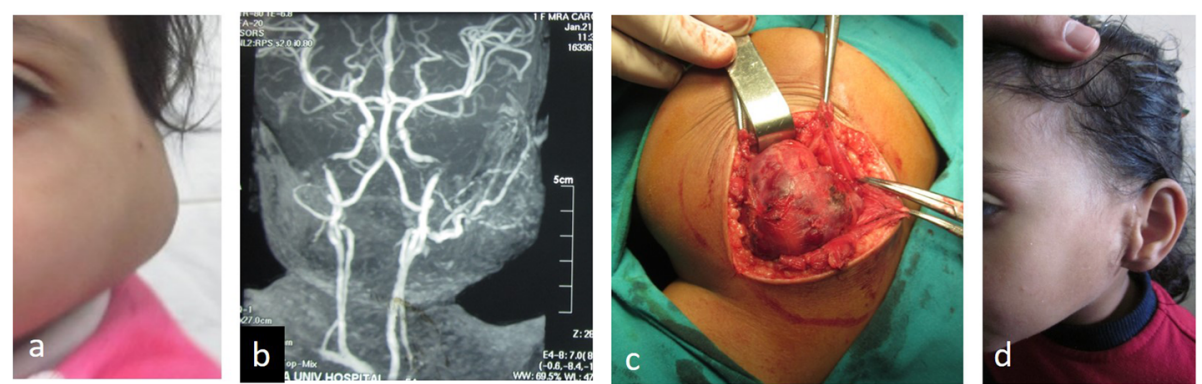

Fig. 8 a Infantile haemangioma in the left parotid of a 12-month-old girl. Failure to respond to medical treatment was an indication for excision at the age of 3 years. $\mathbf{b}$ MR angiography showing the feeding artery that was embolized by interventional radiologist $24 \mathrm{~h}$ before surgery to decrease bleeding during operation. c Care should be given to avoid fascial nerve injury during operation. d Outcome after excision of parotid haemangioma

phase of the tumour in some regions of the body. The main concern when managing $\mathrm{IH}$ is cosmesis. Cosmetic concerns are more pronounced in managing large/diffuse lesions and those affecting the face [2]. Lesions around natural orifices (lips, nose) can cause considerable disfigurement even if not large in size [2]. Lesions around the orbit may obstruct the visual field to a variable extent. Airway involvement by $\mathrm{IH}$ represents a rare but a life-threatening complication [2, 3]. Infantile haemangiomas may be associated with neurological anomalies (PHACE syndrome, occult spinal dysraphism) [2] but were uncommon in this case series as well (3\%).

Spontaneous involution represents a great privilege in manging IH over other vascular anomalies. This can guarantee a favourable outcome at the end for most cases of $\mathrm{IH}$ [15]. The introduction of propranolol for managing complications of $\mathrm{IH}$ during the proliferative phase was a breakthrough [6]. Since its introduction in
2008, propranolol rapidly became the first line of treatment for IH in different centres all over the world [1-3].

The shift of managing vascular anomalies at a specialised multidisciplinary clinic should be highlighted in this report [7, 16, 17]. While the role of conventional surgery in managing these cases has been retreating over the past years [16], our colleagues at the paediatric oncology/haematology speciality were able to introduce new treating modalities that favourably changed the course of disease. At the beginning, systemic corticosteroids were used in managing diffuse haemangiomas, which later have been replaced by propranolol to a great extent. Also, cytotoxic drugs (vincristine, interferon) are used for managing more aggressive vascular tumours (haemangioendotheliomas). Most recently, sirolimus has been introduced as a new hope to control progression of complex vascular anomalies [14]. Another important role for the haematologist is to correct coagulopathies
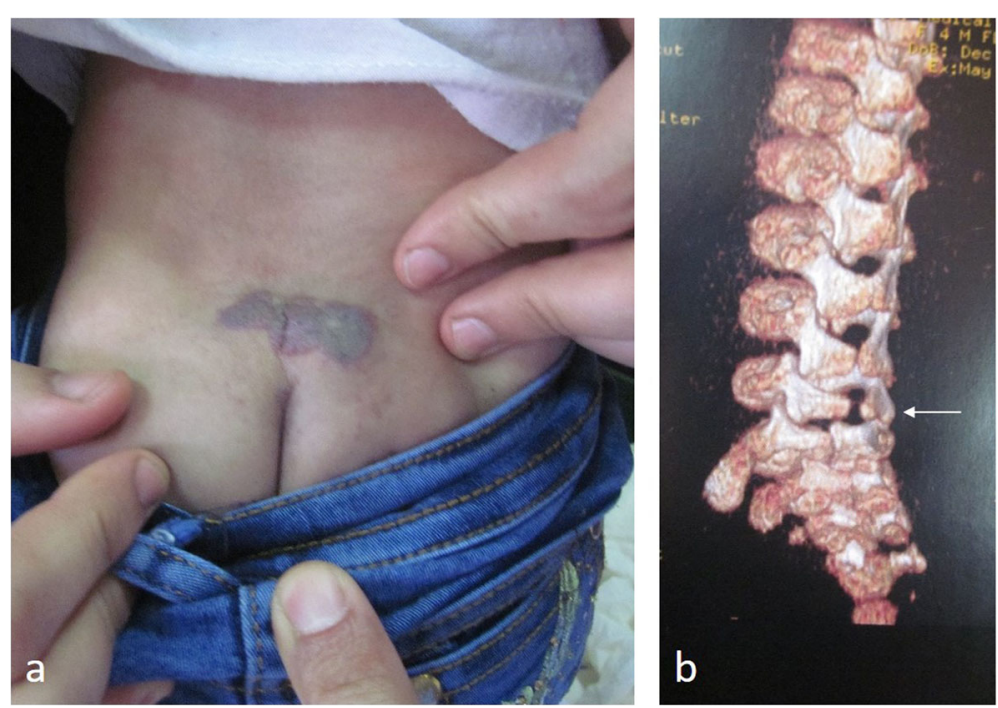

Fig. 9 Infantile haemangioma presenting as a midline back lesion (a) that was associated with spina bifida occulta demonstrated by white arrow in (b) 
(thrombocytopenia, consumption coagulopathy) that can associate vascular anomalies other than $\mathrm{IH}$ [15].

Studying the medical images with experts in the field of paediatric radiology greatly improved our perception and understanding of anatomical details for different vascular anomalies [8]. Also, they provided guidance in choosing the best imaging modality and optimising MRI protocols to suit such a diverse spectrum of anomalies [9]. Interventional radiologists performed preoperative embolization for highly vascular lesions to reduce bleeding during operation and facilitate resection [7, 17].

This report may be criticised being retrospective and the relatively small number of cases included. This may be attributed to available digital archiving that mostly represented cases of $\mathrm{IH}$ having an indication for active intervention (either medical or surgical). Therefore, a selection bias cannot be excluded, yet we would like to emphasise in this report on the benign nature and the successful management protocol for cases of $\mathrm{IH}$. Moreover, we highlighted the successful implementation of a multidisciplinary approach for managing vascular anomalies as an example that can be replicated in different fields of paediatric surgery.

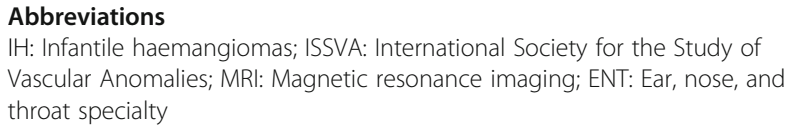
Vascular Anomalies; MRI: Magnetic resonance imaging; ENT: Ear, nose, and throat specialty

\section{Acknowledgements}

None.

\section{Authors' contributions}

All authors have read and approved the manuscript. Study conception and design: AAA. Data acquisition: AAA, IAR, SAM, WAG, HMN. Analysis and data interpretation: AAA, IAR, SAM. Drafting of the manuscript: AAA. Critical revision: OE.

\section{Funding}

None.

\section{Availability of data and materials}

The datasets used and/or analysed during the current study are available from the corresponding author on reasonable request.

\section{Declarations}

\section{Ethics approval and consent to participate}

A written parental consent was taken before operation in all cases. Owing to the retrospective nature of the study, an IRB number was not required, and the study was approved through expedited review by the scientific/ethical committee of the Pediatric Surgery department (Faculty of Medicine, AinShams University).

\section{Consent for publication}

Patient identity did not appear in any part of the manuscript; therefore, consent for publication was not required.

\section{Competing interests}

The authors declare that they have no competing interests.

\section{Author details}

${ }^{1}$ Pediatric Surgery Department, Faculty of Medicine, Ain Shams University, Cairo, Egypt. ${ }^{2}$ Department of Pediatric, Faculty of Medicine, Ain Shams
University, Cairo, Egypt. ${ }^{3}$ Department of Radiodiagnosis, Faculty of Medicine, Ain Shams University, Cairo, Egypt. ${ }^{4}$ Department of Radiodiagnosis (Interventional Radiology Unit), Faculty of Medicine, Ain Shams University, Cairo, Egypt.

Received: 15 September 2020 Accepted: 22 April 2021

Published online: 01 June 2021

\section{References}

1. Gokani VJ, Sivakumar B, Kangesu L (2018) Vascular anomalies. Surgery (Oxford) 36(6):314-323. https://doi.org/10.1016/.mpsur.2018.03.010

2. Strub G, Sidbury R, Bauman N (2018) Vascular tumors: infantile hemangioma. In: Perkins JA, Balakrishnan K (eds) Evidence-based management of head and neck vascular anomalies. Springer Nature, Switzerland, pp 37-46

3. Flors L, Park AW, Norton PT, Hagspiel KD, Leiva-Salinas C (2019) Soft-tissue vascular malformations and tumors. Part 1: classification, role of imaging and high-flow lesions. Radiologia (English edition) 61:4-15. https://doi.org/1 0.1016/j.rxeng.2017.11.001

4. Mulliken JB, Glowacki J (1982) Hemangiomas and vascular malformations in infants and children: a classification based on endothelial characteristics. Plast Reconstr Surg 69(3):412-422. https://doi.org/10.1097/00006534-198203 000-00002

5. Dasgupta R, Fishman SJ (2014) ISSVA classification. Semin Pediatr Surg 23(4): 158-161. https://doi.org/10.1053/j.sempedsurg.2014.06.016

6. Leaute-Labreze C et al (2008) Propranolol for severe hemangiomas of infancy. N Engl J Med. 358(24):2649-2651. https://doi.org/10.1056/ NEJMC0708819

7. Guevara CJ, Alomari Al (2013) Interdisciplinary approach to treatment of vascular anomalies. Tech Vasc Interv Radiol 16(1):55-58. https://doi.org/10.1 053/j.tvir.2013.01.008

8. Mohammad SA, AbouZeid AA, Fawzi AM et al (2017) Magnetic resonance imaging of head and neck vascular anomalies: pearls and pitfalls. Ann Pediatr Surg 13(3):116-124. https://doi.org/10.1097/01.XPS.0000513183.5691 9.bf

9. Mamlouk MD, Nicholson AD, Cooke DL, Hess CP (2017) Tips and tricks to optimize MRI protocols for cutaneous vascular anomalies. Clin Imaging 45: 71-80. https://doi.org/10.1016/j.clinimag.2017.05.019

10. Sadick M, Wohlgemuth WA, Huelse R, Lange B, Henzler T, Schoenberg SO, Sadick H (2017) Interdisciplinary management of head and neck vascular anomalies: clinical presentation, diagnostic findings and minimal invasive therapies. Euro J Radiol Open 4:63-68. https://doi.org/10.1016/j.ejro.2017.05. 001

11. Aly MMD, Hamza AF, Abdel Kader HM, Saafan HA, Ghazy MS, Ragab IA (2015) Therapeutic superiority of combined propranolol with short steroids course over propranolol monotherapy in infantile hemangioma. Eur J Pediatr 174(11):1503-1509. https://doi.org/10.1007/s00431-015-2561-1

12. Herlihy E, Hochman M (2018) Periocular vascular tumors: infantile hemangioma. In: Perkins JA, Balakrishnan K (eds) Evidence-based management of head and neck vascular anomalies. Springer Nature, Switzerland, pp 105-111

13. Elluru RG (2018) Vascular tumors of the airway. In: Perkins JA, Balakrishnan $\mathrm{K}$ (eds) Evidence-based management of head and neck vascular anomalies. Springer Nature, Switzerland, pp 131-137

14. Mizuno T, Emoto C, Fukuda T, Hammill AM, Adams DM, Vinks AA (2017) Model-based precision dosing of sirolimus in pediatric patients with vascular anomalies. Euro J Pharm Sci 109:s124-s131. https://doi.org/10.1016/ j.ejps.2017.05.037

15. Greene AK, Liu AS, Mulliken JB, Chalache K, Fishman SJ (2011) Vascular anomalies in 5621 patients: guidelines for referral. J Pediatr Surg 46(9):17841789. https://doi.org/10.1016/j.jpedsurg.2011.05.006

16. Adams DM, Fishman SJ (2017) Late sequelae and long-term outcomes of vascular anomalies. Semin Pediatr Surg 26(5):317-321. https://doi.org/10.1 053/j.sempedsurg.2017.09.007

17. Mamlouk MD, Lee PW (2018) Developing a multidisciplinary vascular anomaly clinic and reviewing the radiologist's clinic role. Curr Probl Diagn Radiol 47(6):378-381. https://doi.org/10.1067/j.cpradiol.2017.10.009

\section{Publisher's Note}

Springer Nature remains neutral with regard to jurisdictional claims in published maps and institutional affiliations. 